\title{
Is ideomotor apraxia the outcome of damage to well-defined regions of the left hemisphere?
}

\author{
Neuropsychological study of CAT correlation
}

\author{
A BASSO, C LUZZATTI, H SPINNLER \\ From the Neuropsychology Centre of Milan University, Milan, Italy
}

SUMMARY A CAT scan was recorded from 123 patients with left hemisphere damage from stroke. They were divided into four groups according to presence or absence of ideomotor apraxia and length of illness (15 to 90 days and over 90 days). The lesions were mapped and compared in the four experimental groups for anteroposterior dimension, lesion depth-deep-seated lesions deing separated from lesions with a superficial component-and position with respect to the Sylvian fissure for lesions encroaching on the surface. In the anteroposterior dimension there is no material bifference in the distribution of the lesions with respect to length of illness. Moreover, any difference is hardly detectable between the profiles for patients with and without ideomotor apraxia except for the higher frequency of deep lesions in the non-apraxic group. The same holds true for "small" lesions.

One of the oldest and most fascinating aims of clinical neuropsychology is to establish anatomopsychological correlations. The classical approach based on single necropsy cases selected for behavioural impairment-that is, for the presence of an outstanding neuropsychological impairment -supplied very precise information on the anatomy of the lesions but, by definition, could not furnish inferential data. Another approach has been to take large series of unselected hemisphere-damaged patients, divide them into groups according to the topography suggested by their neurological or instrumental signs, put them through standard tests, and subject the group results to statistical analysis. Nowadays CAT scanning permits a check on the putative lesion area, and its systematic use enables us to consider the crucial problem raised by von Monakov ${ }^{1}$ and by Brun" of the "negative" cases-that is, those in which the presumed critical area does not fit the impaired ability. We have attempted a retrospective study of the records of our Aphasia Unit (this on left hemisphere-damaged

Address for reprint requests: Dr A Basso, Neuropsychology Centre of Milan University, Via F. Sforza, 35, 20122 Milano, Italy.

Accepted 12 June 1979 patients only), focusing our attention on ideomotor apraxia. We are well aware that CAT localisation of a cerebrovascular lesion cannot be anything like as accurate as histological localisation, for only occasionally does a CAT assessment give sufficient information on the extent of a lesicn in the grey and white matter structures regarded as functionally important for the ability in question. But we thought it would be worth attempting a generalisation of the information drawn by Liepmann, ${ }^{34}$ Niessl von Mayendorff," Heilbronner, ${ }^{6}$ and more recently by Ajuriaguerra et $a l,{ }^{7}$ Heilman et $a l,{ }^{8}$ and Geschwind, ${ }^{9}$ from a few selected cases to a large series of strictly unselected cases.

The aims of the study were two. The first was to ascertain whether the presence or absence of ideomotor apraxia in left hemisphere-damaged $(\mathrm{L} / \mathrm{pts})$ is related to the CAT locus of a cerebrovascular lesion. Here two points were considered: (1) the anteroposterior dimension of the left hemisphere lesion and its depth, and (2) the lesions encroaching on the surface of the hemisphere with respect to the Sylvian fissure. The second aim was to establish whether the presence/ absence of ideomotor apraxia is related to a CAT index representing the volume of destroyed cerebral tissue. 


\section{Subjects and methods}

The cases were drawn from a continuous series of 279 left hemisphere-damaged patients who suffered their first stroke (either haemorrhagic or ischaemic), entering the wards of the Neurological Department of Milan University (163) or examined as outpatients (116) in our Aphasia Unit during the period from January 1977 to June 1978. We excluded $124 \mathrm{~L} / \mathrm{pts}$ for the following reasons: 15 because of more than $20 \%$ left handedness on the Edinburgh inventory, 59 because of clinical or CAT scan evidence of bilateral lesions, 20 because of unwillingness to be tested, 25 because of movement artefacts on the CAT scan, two because of the presence of a crossed aphasia, and three for concomitant epilepsy. Another 32 were excluded on the following grounds: five had negative CAT scan and 27 underwent CAT scanning and apraxia testing less than 15 days after the stroke. When CAT scanning is done in the first days and the cerebrovascular lesion is ischaemic, it may be normal (neither hypodense nor hyperdense) or show oedema and it can be difficult to localise the real extent of the lesion; finally, patients might not lie still and the scan would be blurred. Moreover, major or minor vigilance impairments, often present in the first 15 days, can make formal testing for apraxia unreliable. Table 1 gives the current data for $\mathrm{L} / \mathrm{pts}$ entering this study.

The $123 \mathrm{~L} / \mathrm{pts}$ entering the study were divided into two groups according to the interval between stroke and examination: 15 to 90 days (65 patients) and over 90 days (58 patients). The purpose of this was to take into account the relationship between the CAT localisation and the possible ultimate functional recovery, for it is well known that apraxia may be clinically apparent within a few days of a brain lesion and then disappear. The groups were then divided according to performance on the tests. Thus, four experimental groups were formed (table 1). It is worth noting that the lesion localisations were compared between patients with and without ideomotor apraxia divided by illness length (as detailed above) and between severe and mild apraxic patients.

\section{TESTING PROCEDURES FOR IDEOMOTOR APRAXIA}

All $L / p t s$ underwent testing for ideomotor apraxia according to the routine of our Aphasia Unit. ${ }^{11}$ They were asked to imitate (with the armhand ipsilateral to the damaged hemisphere) 10 different single gestures. Each item scored two points (immediate correct response), one point (correct response preceded by hesitation and protracted latency during which wrong or unsuccessful movements may te made, or performance conceptually correct, but actual movements somewhat inaccurate or awkward) and no points (any other type of error). The best score is thus 20 . Patients with scores below a cut-off score of 17 (obtained by De Renzi et al, on 40 control subjects and 45 right hemisphere-damaged patients) are considered to be apraxic. Apraxic patients were further divided into mildly and severely apraxic according to whether their score on our apraxia scale fell over or under the median value (12). Table 2 shows the distribution of the 123 $\mathrm{L} / \mathrm{pts}$ entering the study on our 0-20 apraxia scale as well as their distribution according to the apraxia cut-off score (17) and the median value (12).

\section{CAT SCAN INVESTIGATIONS}

Within 10 days of testing for ideomotor apraxia, all patients underwent a CAT scan. The lesions were mapped by the method of Luzzatti et al. ${ }^{12}$ We decided to read the maximum anteroposterior (AP) dimension of the lesion on a grid of size equal to that of the lateral diagram used for mapping the lesion. These grids are divided into 60 equal columns, numbered 1 to 60 (see fig 1)

Table 1 Means and SD of age, years of schooling, length of illness, and Token Test scores of the four cxperimental groups

\begin{tabular}{|c|c|c|c|c|}
\hline \multirow[b]{2}{*}{ Variables } & \multicolumn{4}{|c|}{ Patients $(n=123)$} \\
\hline & $\begin{array}{l}\text { With ideom } \\
15-90 \text { days } \\
(n=30)\end{array}$ & $\begin{array}{l}\text { apraxia } n=48 \\
\text { More than } \\
90 \text { days } \\
(n=18)\end{array}$ & $\begin{array}{l}\text { Without ide } \\
15-90 \text { days } \\
(n=35)\end{array}$ & $\begin{array}{l}\text { apraxia } n=75 \\
\text { More than } \\
90 \text { days } \\
(n=40)\end{array}$ \\
\hline $\begin{array}{l}\text { Age (yr) } \\
\text { Duration of schooling (yr) } \\
\text { Length of } i \text { !ness (d) } \\
\text { Token test* score (up to } 36 \text { ) }\end{array}$ & $\begin{array}{l}56.7 \pm 12.5 \\
7.2 \pm 4.7 \\
45.8 \pm 21.0 \\
10.0 \pm 7.3\end{array}$ & $\begin{aligned} 59.8 & \pm 8.8 \\
6.8 & \pm 4.4 \\
370.3 & \pm 271.2 \\
10.7 & \pm 9.3\end{aligned}$ & $\begin{array}{l}53.9 \pm 12.5 \\
8.5 \pm 4.4 \\
39.8 \pm 19.2 \\
21.3 \pm 8.3\end{array}$ & $\begin{array}{c}53.3 \pm 16.0 \\
7.4 \pm 3.9 \\
511.8 \pm 386.4 \\
20.6 \pm 7.6\end{array}$ \\
\hline
\end{tabular}

\footnotetext{
* From De Renzi and Faglioni 10.
} 
Table 2 Distribution of the apraxia score of the four left hemisphere subgroups

\begin{tabular}{|c|c|c|}
\hline Score & $\begin{array}{l}\text { Stroke between } \\
15 \text { and } 90 \text { days } \\
(n=65)\end{array}$ & $\begin{array}{l}\text { Stroke after } \\
90 \text { days } \\
(n=58)\end{array}$ \\
\hline 20 & 29 & 27 \\
\hline 19 & 2 & 2 \\
\hline 18 & 2 & 6 \\
\hline 17 & 2 & 5 \\
\hline 16 & 6 & 2 \\
\hline 15 & 5 & 1 \\
\hline 14 & 5 & 1 \\
\hline 13 & 2 & 2 \\
\hline+-- & $---\cdots$ & ---- \\
\hline 12 & 1 & 2 \\
\hline 11 & 0 & 0 \\
\hline 10 & 1 & 0 \\
\hline 9 & 0 & 0 \\
\hline 8 & 2 & 4 \\
\hline 7 & i & 1 \\
\hline 6 & 2 & 0 \\
\hline 5 & $i$ & 0 \\
\hline 4 & i & 1 \\
\hline 3 & i & $\mathbf{0}$ \\
\hline 2 & 2 & 1 \\
\hline$i$ & 0 & 0 \\
\hline 0 & 0 & 3 \\
\hline
\end{tabular}

*Continuous line $=$ apraxia cut-off score.

†Dashed line $=$ median value of the 48 patients with ideomotor apraxia.

from the frontal to the occipital pole. Each lesion was mapped by two numbers: one indicating where it started and the other where it ended in the anteroposterior dimension. Moreover, we plotted separately on the grid the superficial (less than $20 \mathrm{~mm}$ from the surface) and the deep components of each lesion; most of the lesions had both superficial and deep components (90) or only deep ones (26), superficial lesions only being rare (seven). For the four experimental grcups (and for the surerficial and deep components of each lesion) we then counted how

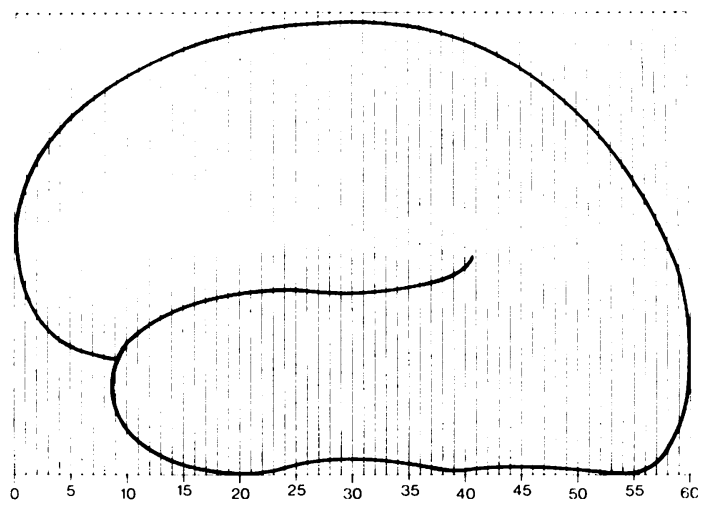

Fig 1 Grid, divided into 60 columns, used to localise lesions in the anteroposterior dimension. many times the lesions fell in each of the 60 columns. Figure 2 represents the percentage distribution of the lesions in each column in the four experimental groups. The continuous line represents the superficial component and the dashed line the deep one. Lesions which are both superficial and deep are represented twice by means of the continuous and the dashed line.

In addition to the anteroposterior dimension the lesions were localised by two other parameters: (1) lesion depth-purely deep-seated (26) lesions were separated from lesions with a superficial component (97, including the seven purely superficial lesions); (2) the 97 lesions encroaching on the left hemisphere surface were then subdivided by position with respect to the Sylvian fissure-below (16), above (21), below and above (50), behind (10).

The volume of the lesion was calculated on the basis of the number of EMI-pixels (the dimensions of the pixel which we used are: $1.25 \times$ $1.25 \times 13 \mathrm{~mm}$ ) included in each slice of the pathological area. The perimeter of the lesion was delimited for each slice on the computer printout and the area was calculated summing up the number of pixels. The volume was the sum of the lesicn's areas of each slice. Possible sources of error in this procedure are related to the partial volume phenomenon and to difficulty in delimiting the pathological area precisely.

\section{Results}

Figure 2 shows the four histograms by which the anteroposterior distribution of all CAT-assessed lesions were plotted. They belong to $123 \mathrm{~L} / \mathrm{pts}$, divided by presence or absence of ideomotor apraxia and length of illness (15 to 90 days and over 90 days from stroke to testing for ideomotor apraxia). Each histogram is made up of two profiles, one for the deep-seated and the other for the superficial component of the left hemisphere lesions. For each point of the histogram, the height of the column represents the percentage of patients with a lesion at that point (from 1 to 60 ); consequently, for example, the highest dashed column represents the point where most patients have only a deep lesion (or a deep component). It is clear that there is virtually no point (or at the best the extreme polar regions only) in the anteroposterior dimension that fails to have a lesion. The bulk of the lesions are around point 30 (with large approximation where the Rolandic meets the Sylvian fissure). This simply reflects the heavy preponderance of Sylvian artery strokes. Posterior artery strokes were rare in our series 
$(n=10)$, while anterior artery strokes were totally absent. This might simply reflect the fact that polar strokes are actually less frequent than central ones or that lesions in the frontal or occipital poles often fail to cause an impairment severe enough to bring the patient to the hospital.

There was hardly any difference between the profiles for patients with ideomotor apraxia (48)
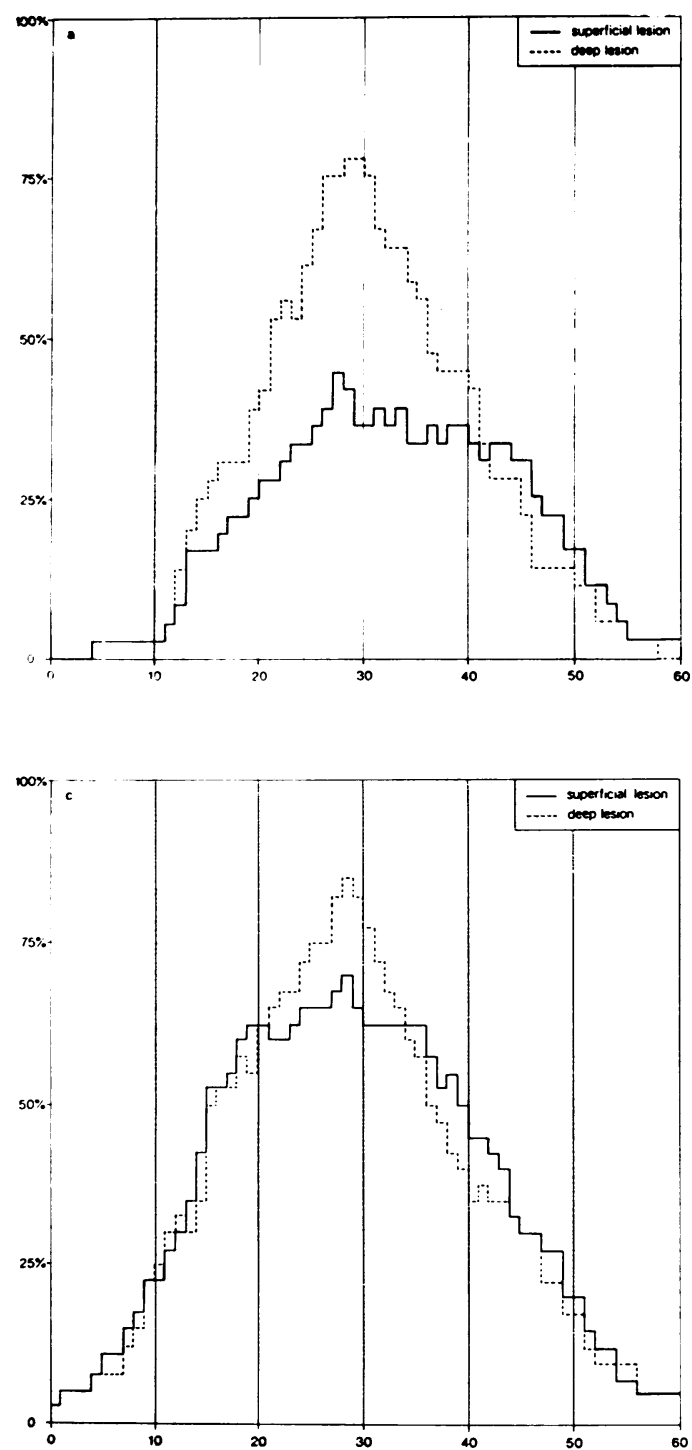

and those without it (75), except for the higher frequency of deep lesions in the latter group. There was no material difference in the distribution of the lesions with respect to length of illness. This subdivision has therefore been omitted for the other dimensions by which the lesions have been plotted. The same results obtain when we consider only severely apraxic patients, the
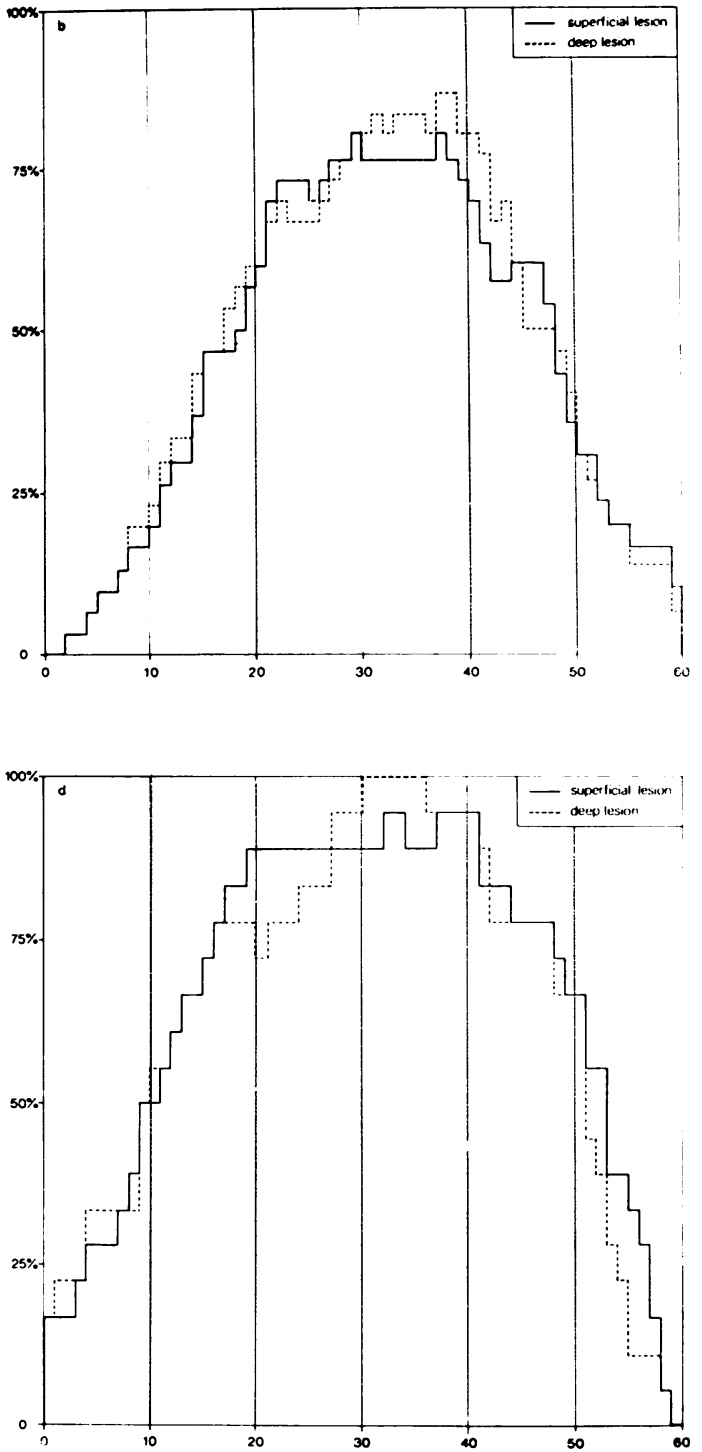

Fig 2 Histograms representing the site of lesions in 123 patients divided into four experimental groups. The site of the lesions in the anteroposterior dimension is represented in the abscissa; the ordinate gives the percentage of patients with lesion at that point. (a) Patients without ideomotor apraxia, 15-90 days (35); (b) patil nts with ideomotor apraxia, 15-90 days (30); (c) patients without ideomotor apraxia, more than 90 day: (40); (d) patients with ideomotor apraxia, more than 90 days (18). 
cnly difference being that lesions in these patients were larger, and therefore a flatter histogram obtains (fig 3).
Figure 4 gives the same kind of distribution of lesions for cases (eight with and 43 without ideomotor apraxia) selected for the conventionally

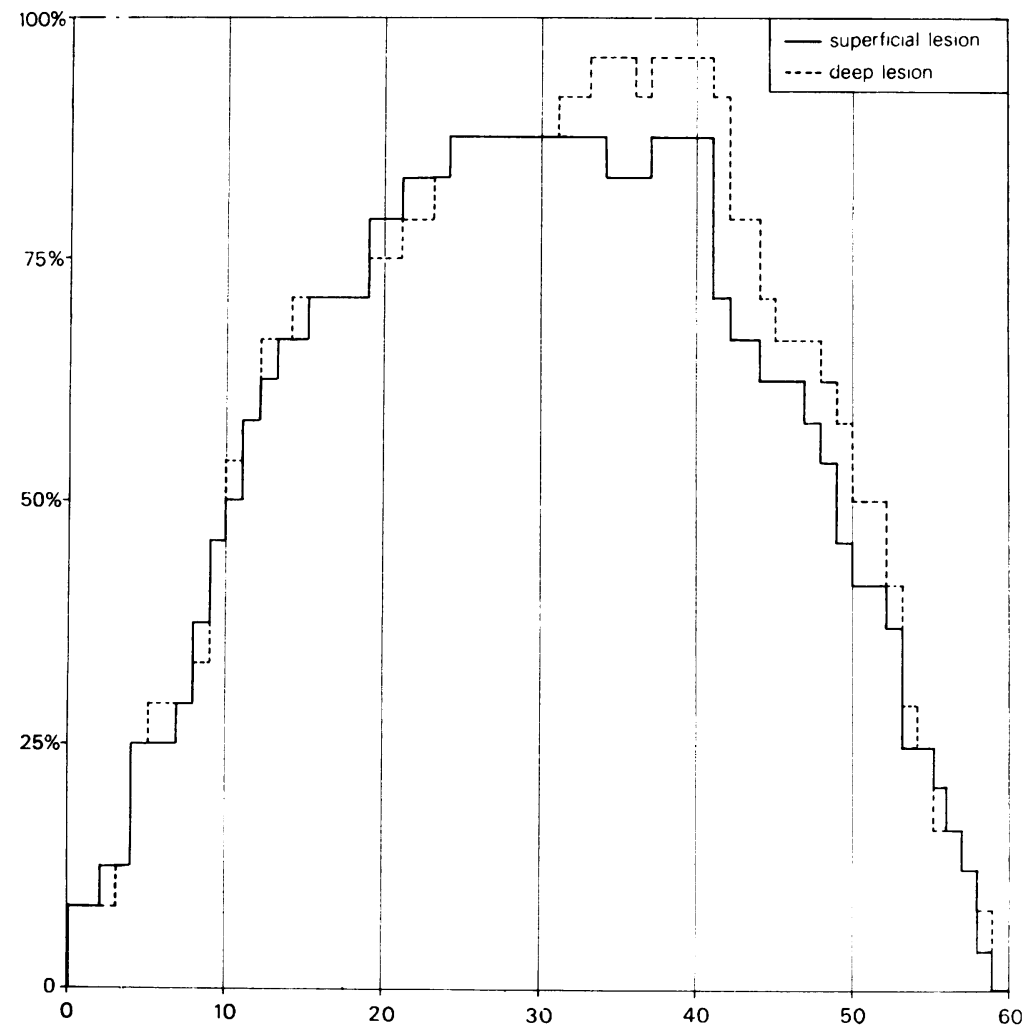

Fig 3 Histogram, as in fig 2, for severely apraxic patients only (24).
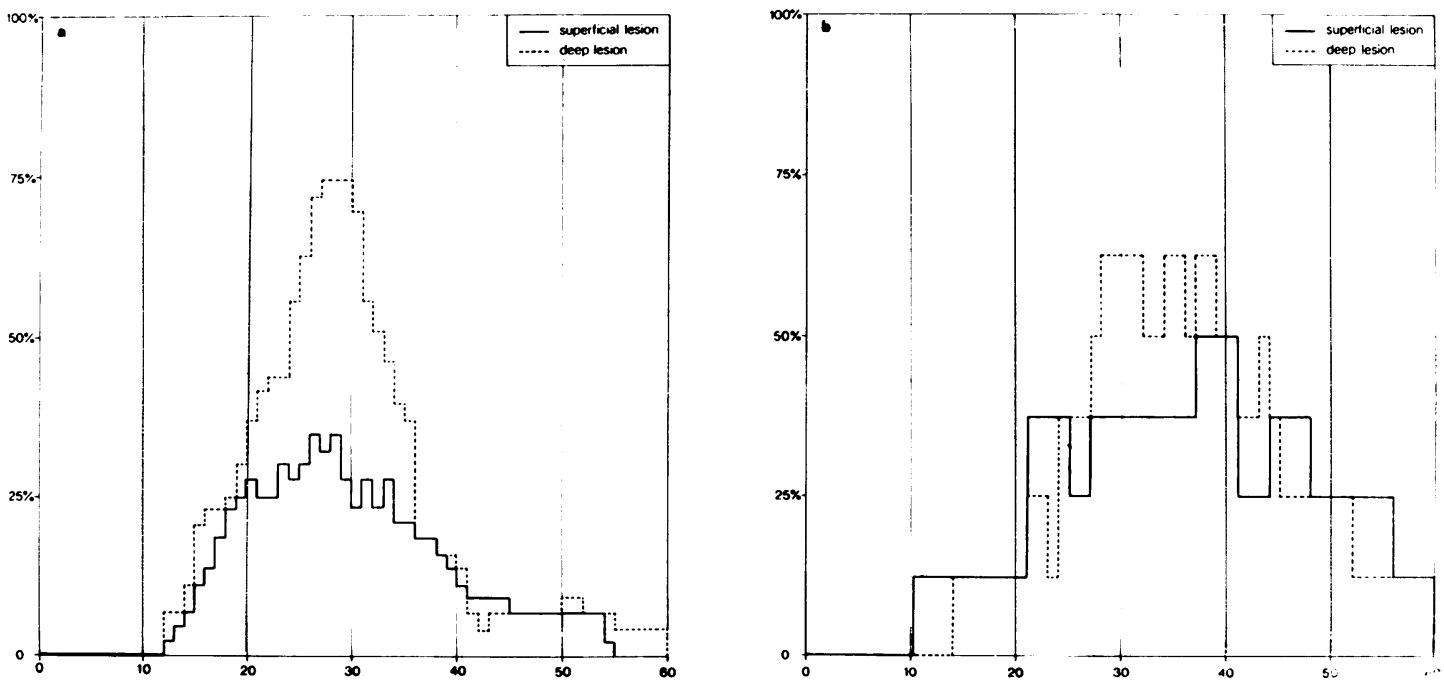

Fig 4 Histograms, as in fig 2, for "small" lesions only. (a) Patients without ideomotor apraxia (43); (b) patients with ideomotor apraxia (8). 
defined "smallness" of their lesions (less than $40 \%$ of the anteroposterior index). There is again an impressive similarity of profile between those with and without the disorder, which is clearly at variance with the view that one or more areas critical for ideomotor apraxia lie in highly predictable regions.

Table 3 shows the L/pts (123) divided by presence or absence of ideomotor apraxia and encroachment or not of the lesion on the cerebral surface. Purely deep lesions were rarely associated with ideomotor apraxia $\left(\chi^{2}=7 \cdot 743\right.$, $\mathrm{df}=1, \mathrm{p}<0.01$ ).

Table 3 Distribution of patients with and without ideomotor apraxia according to location of lesions

\begin{tabular}{lll}
\hline Level of lesion & $\begin{array}{l}\text { Patients } \\
\text { without } \\
\text { ideomotor apraxia } \\
(n=75)\end{array}$ & $\begin{array}{l}\text { Patients } \\
\text { with } \\
\text { ideomotor apraxia } \\
(n=48)\end{array}$ \\
\hline $\begin{array}{l}\text { Only deep lesions }(\mathrm{n}=26) \\
\begin{array}{l}\text { Lesions encroaching on the } \\
\text { surface }(\mathrm{n}=97)\end{array}\end{array}$ & 22 & 4 \\
\hline
\end{tabular}

Table 4 concerns the $97 \mathrm{~L} / \mathrm{pts}$ with lesions encroaching on the cerebral surface. They are divided by position of the lesion with respect to the Sylvian fissure (below, above, below and above, behind) and presence or absence of ideomotor apraxia. It turns out that none of these anatomical positions fits the behavioural subdivision onto patients with and without apraxia $\left(\chi^{2}=5 \cdot 177, \mathrm{df}=3, \mathrm{P}: \mathrm{NS}\right)$.

Figure 5 sets the distribution of lesion volumes

Table 4 Distribution of patients with and without ideomotor apraxia according to location of lesions on the cerebral surface

\begin{tabular}{lll}
\hline Location of lesion & $\begin{array}{l}\text { Patients } \\
\text { without } \\
\text { ideomotor apraxia } \\
(n=53)\end{array}$ & $\begin{array}{l}\text { Patients } \\
\text { with } \\
\text { ideomotor apraxia } \\
(n=44)\end{array}$ \\
\hline $\begin{array}{l}\text { Suprasylvian }(n=21) \\
\text { Infrasylvian }(n=16)\end{array}$ & 11 & 10 \\
$\begin{array}{l}\text { Supra-and } \\
\text { infrasylvian }(n=50)\end{array}$ & 12 & 4 \\
Retrosylvian $(n=10)$ & 23 & 27 \\
\hline
\end{tabular}

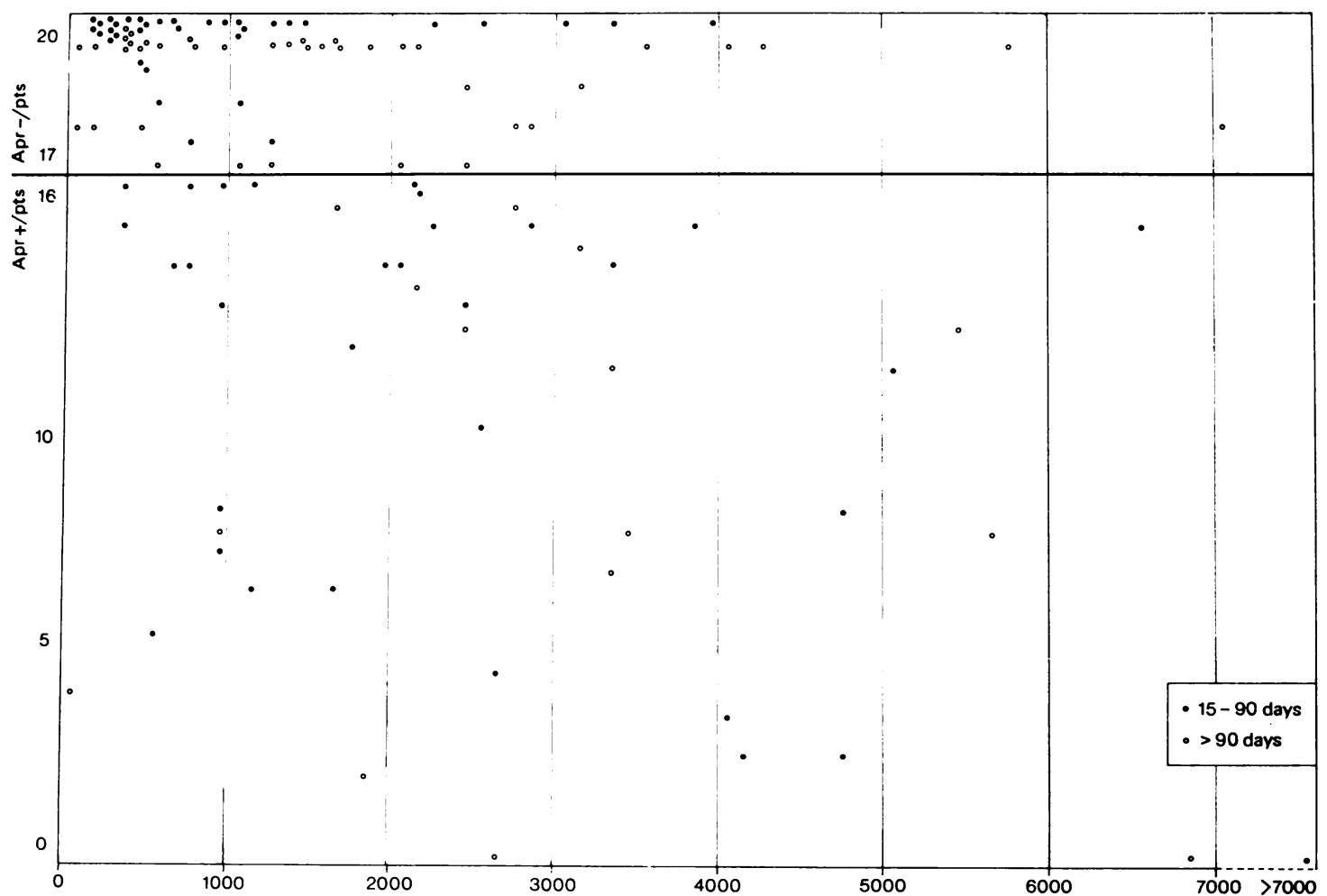

Fig 5 Distribution of lesion volume (expressed in number of pixels) of 123 patients against eupraxia score. Volume is represented in the abscissa, the eupraxia score in the ordinate (the line representing the apraxia cut-off score). 
of all $\mathrm{L} / \mathrm{pts}$ against the apraxia scores. As it can be seen there is no easily detectable relationship between apraxia score and lesion volume.

\section{Discussion}

The main value of attempts like ours to correlate the locus and extent of a hemisphere lesion and the presence or absence of a neuropsychological defect is the absence of nearly any neuropsychological selection of the patients entering the study, an approach diametrically opposed to the classical one.

If we consider the map of lesions in patients with ideomotor apraxia, we find something approximating to the classical notion of apraxia localisation within the left hemisphere-namely, in the anterior, central, and suprasylvian retrorolandic areas, ${ }^{14}$ disconnection of which from the central executor region has been regarded as responsible for apraxia. ${ }^{34}$ So the correlations of patients with ideomotor apraxia tally with the "positive" clinico-anatomical correlations found by von Monakov' for his 10 apraxia cases (“. . . in Bezug auf die Lokalisation der Apraxia käme jeder Vertreter einer besonderen Lokalisationsweise . . . auf seine Rechnung"). The same is true if we consider the maps of severely apraxic patients - that is, of patients whose behavioural impairment is probably more similar to that of the single necropsy cases (fig 3).

Turning to the patients who did not have ideomotor apraxia, we find a pattern of lesion distribution similar to that for those with the disorder which also agrees pretty well with von Monakov's rather sceptical conclusions. There is no such agreement in the case of deep-seated lesions which are often unrelated to apraxia (but see Kimura ${ }^{15}$ ). These usually lie either within the striatum or, more often, deeper, and they nearly always encroach on the inner capsule. Since the connections classically regarded as bearing on apraxia are more superficial, the disagreement may be more apparent than real. A similar situation arises when "small" lesions belonging to patients either with or without ideomotor apraxia are considered separately. Such lesions have been regarded hypothetically as capable of affecting very circumscribed crucial structures almost selectively.

To illustrate our findings better we selected six patients with and six without ideomotor apraxia, all of whom had small scattered and topographically equivalent lesions; fig 6 shows how similar lesions can cause or not cause an apraxic behaviour. Pure small frontal lesions are not illustrated here as they were not present in our series.

Although our routine testing for ideomotor apraxia is only a rough guide to apraxia, mainly because there is no evaluation of gesture sequencing, we do not think it is responsible for the negative outcome of our study. This is supported by the conclusions of De Renzi $e t a l^{16}$ who query the paramount value of motor sequence tasks ${ }^{17}$ in detecting apraxia. We do not mean that a more flexible assessment of apraxia, perhaps with allowance for a different classifcation of apraxia syndromes, would not provide somewhat different results, as was the case with aphasia localisations. ${ }^{13}$ However, this is hypothetical and calls for a prospective study which is in progress.

Our findings need checking because they cast doubt on any strictly localising approach to ideomotor apraxia and at the same time fail to suggest what is the anatomical difference between apraxic and non-apraxic patients. Our feeling is that apraxia is the outcome of widespread disruption in the left hemisphere and in some callosal connections or even in the right hemisphere. The CAT scan approach of lumping the lesions together and localising them in one or more leftsided regions failed to elicit the crucial topography, whether because the network of critical connections is too diffuse (that is, the opposite of what is meant by a "centre") or because CAT scanning is not yet suitable for demonstrating the relevant highly circumscribed regions, we do not know. Since the question is open, we may discuss three possible explanations of our findings.

1. Although there may be circumscribed "centres" for eupraxia in the left hemisphere (for example, parietal inferior and premotor centres), their location probably varies or, if the location is the same, it will rarely show up on the routine CAT map at the same point. Therefore the "critical areas" are hit unpredictably by a single stroke with a known CAT localisation, a supposition that would tie in surprisingly well with "negative" correlations (that is, absence of apraxia in presence of a lesion in the areas predicted by the "positive" cases) contributed more than half a century ago and strongly emphasised by von Monakov in his thoughtful dispute against what he called the "anatomical psychology" of Wernicke's school.

2. Discrete interruptions of fibres from the right hemisphere may deprive the damaged left hemisphere of some form of aid, thereby causing apraxia. That the right hemisphere is in some 

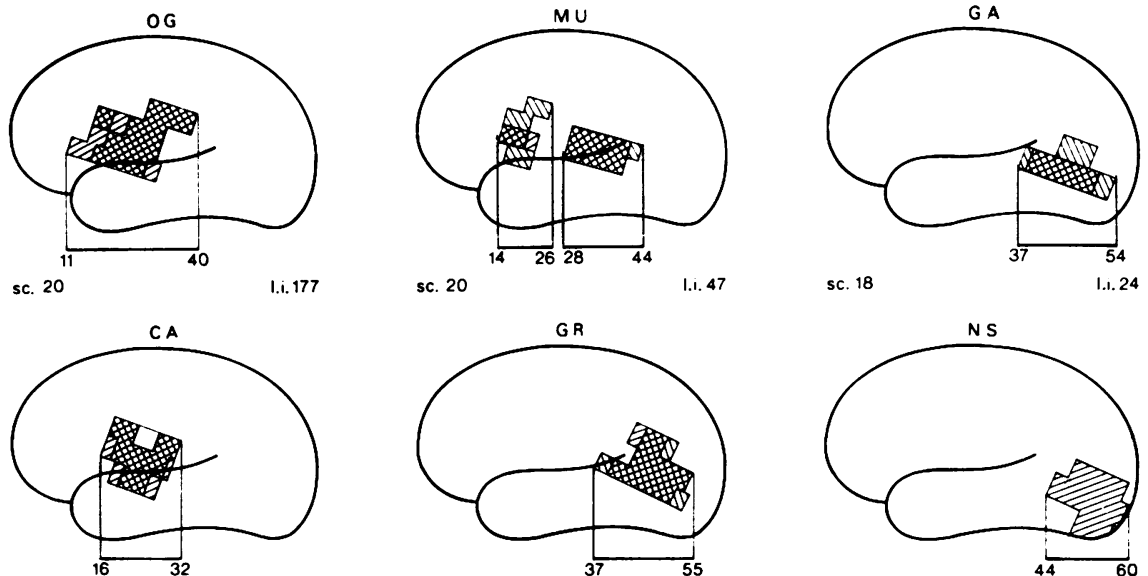

sc. 20
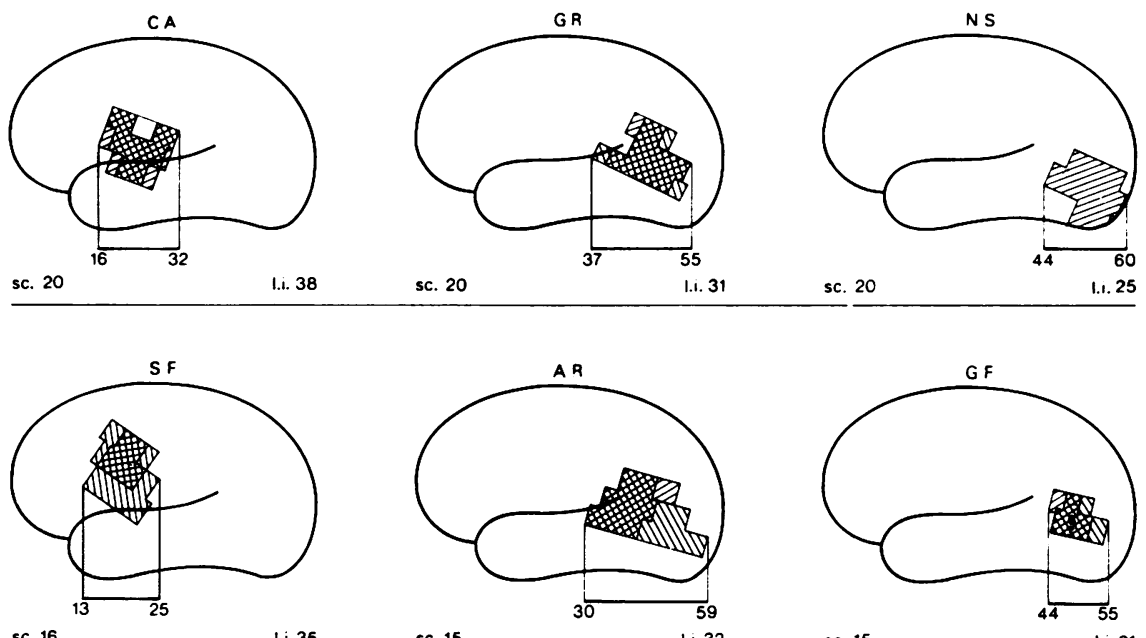

sc. 20

I.i. 31
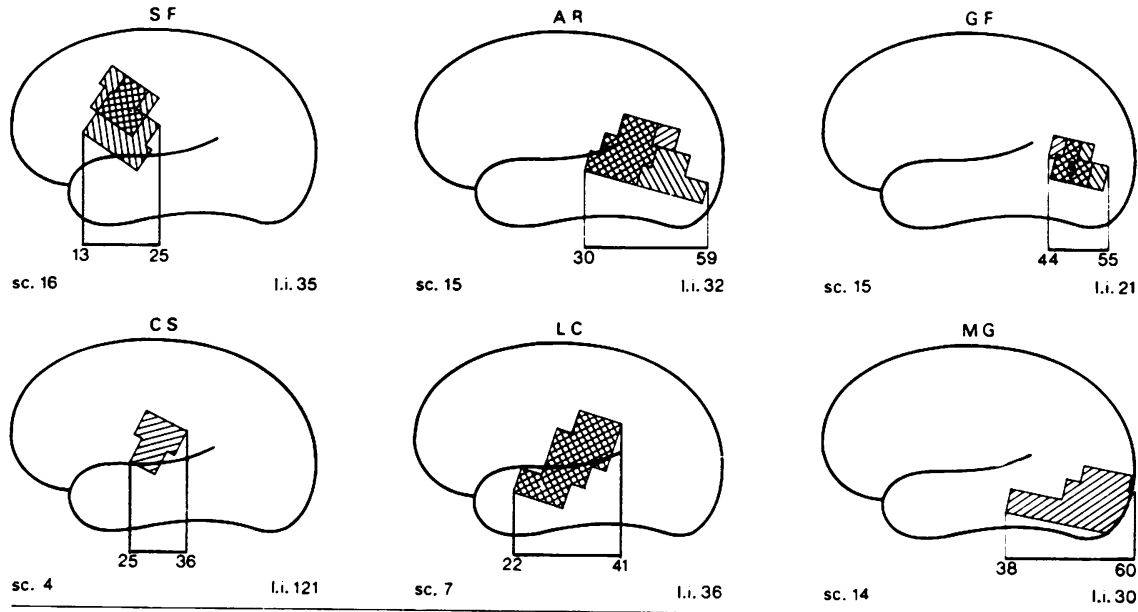

\begin{tabular}{ll} 
sc. 4 & 1.i. $121 \quad$ sc. 7 \\
\hline$\square$ Deep lesion & Superficial lesion
\end{tabular}

Fig 6 Locus, extent, and anteroposterior diameter of brain lesions in six patients without (upper diagram) and six patients with (lower diagram) ideomotor apraxia. Maps reconstructed from CAT scans. sc =apraxia score, li=length of illness in days.

measure involved in eupraxia is supported by the findings of von Monakov' ${ }^{1}$ and Morlaâs ${ }^{18}$ as well as by the more recent work of Dee et $a l^{19}$ and De Renxi et al. ${ }^{16}$ It may be that what is critical for apraxia is not so much the localisation of the bulk of the lesions as of a portion of it (which could be tiny) that disrupts midcallosal fibres. Our plotting could yield little information on such minute but critical damage and on how it is related to the presence or absence of ideomotor apraxia. In our prospective study, which includes right hemisphere-damaged patients and uses a more suitable CAT scan approach (for example, frontal cuts), we are considering the relative importance of remaining sound to damaged parenchyma.

3. Ideomotor apraxia may be the consequence of some sort of "mass action" on Lashley's lines, ${ }^{20}$ in which case only massive left hemisphere lesions would be expected to give rise to apraxia. lesions large enough to deprive the left hemisphere of sufficient healthy tissue to overcome the outcome of the massive lesion. ${ }^{15}$ However, the data in fig 5 do not support this hypothesis, although there is some evidence for a 
correlation between large lesions and ideomotor apraxia. Against this, some of our patients had extremely small lesions and yet their apraxia was consistently apparent throughout the 12 month period of observation.

A future task of neuropsychological research may well be the singling out of the abilities that depend strictly on a given region of the brain from those with broader and less constant anatomical ties. This differentiation might help to explain why it is that after some lesions, such as left temporal lesions, function is slowly and only partially regained while after others, such as right carrefour lesions, function can be taken over by ipsilateral contralateral structures or both within a few days. The fact remains that a large number of stroke patients are permanently incapacitated and that so far no anatomical peculiarity, apart from bilateral lesions, can explain why.

We are grateful to $\mathrm{Mr}$ Ettore Manacorda who designed the illustrations. This work was supported by a grant from the Consiglio Nazionale delle Ricerche.

\section{References}

1 von Monakov C. Die Lokalisation im Grosshirn und der Abbau der Funktion durch kortikale Herde. Wiesbaden: JF Bergmann, 1914.

2 Brun R. Klinische und anatomische Studien über Apraxie. Zürich: Arbeit des Hirnanatomischen Institut, 1922.

3 Liepmann H. Die linke Hemisphaere und das Handeln. Münchener medizinische Wochenschrift 1905; 52:2322-6 and 2375-8.

4 Liepmann H. Der weitere Krankheitsverlauf bei dem einseitig Apraktischem und der Gehirnbefund auf Grund von Serienschnitten. Monatsschrift für Psychiatrie und Neurologie 1906; 19:217-43.

5 Niessxl von Mayendorf E. Die Diagnose auf Erkrankung der linken Gyrusangularis. Monats- schrift für Psychiatrie und Neurologie 1907; 22:145-57 and 225-64.

6 Heilbronner K. Die aphasischen, apraktischen und agnostischen Störungen. In: Handbuch der Neurologie, vol 1. Berlin: Springer, 1910; 9821093.

7 Ajuriaguerra J, Hécaen H, Angelergues E. Les apraxies, variétés cliniques et latéralisation lésionelle. Revue Neurologique 1960; 102:499566.

8 Heilman KM, Coyle JM, Gonyea EF, Geschwind N. Apraxia and agraphia in a left-hander. Brain 1973; 96:21-8.

9 Geschwind N. The apraxias: neural mechanisms of disorders of learned movements. American Scientist 1975; 63:188-95.

10 De Renzi E, Faglioni P. Normative data and screening power of a shortened version of the Token Test. Cortex 1978; 14:41-9.

11 De Renzi E, Pieczuro A, Vignolo LA. Ideational apraxia: a quantitative study. Neuropsychologia 1968; 6:41-52.

12 Luzzatti C, Scotti G, Gettoni A. Further suggestions for cerebral CT-localization. Cortex 1979; in press.

13 Basso A, Salvolini U, Vignolo LA. La localizzezione dei sintomiafasici: prime experienze con l'Emi-scanner. Rivista di Patologia Nervosa $e$ Mentale 1979; in press.

14 Faglioni P. Aprassia: In: Neuropsicologia Clinica, Milano: Franco Angeli, 1977: 67-135.

15 Kimura D. Neuromotor mechanisms in the evolution of human communication. University of Western Ontario, Department of Psychology, Research Bulletin 1978; 454.

16 De Renzi E, Motti F, Nichelli P. Imitating gestures: a quantitative approach to ideomotor apraxia. Arch Neurol 1980; in press.

17 Kimura D, Archibald Y. Motor functions of the left hemisphere. Brain 1974; 97:337-50.

18 Morlaâs J. Contribution à l'étude de l'apraxie. Thèse de Paris, 1928.

19 Dee HL, Benton AL, Van Allen MW. Apraxia in relation to hemispheric locus of lesion and aphasia. Transactions of the American Neurological Association 1970; 95:147-50.

20 Lashley KS. Brain Mechanisms and Intelligence. Chicago: University of Chicago Press, 1929. 